\title{
The Online Publishing Strategies in Improving the Higher Education Institution Ranking: A Case Study of PGRI University of Yogyakarta
}

\author{
Mohamed N. A. Azman ${ }^{1 *}$, Septian A. Permana ${ }^{2}$, Padrul Jana ${ }^{3}$, Muhammad A. Al-Muhsin ${ }^{4}$ \\ Faculty of Technical and Vocational, Universiti Pendidikan Sultan Idris, Tanjung Malim, Perak, Malaysia \\ 2,3 Universitas PGRI Yogyakarta, Daerah Istimewa Yogyakarta 55182, Indonesia \\ ${ }^{4}$ Faculty of Languages and Communication, Universiti Pendidikan Sultan Idris, Tanjung Malim, Perak, Malaysia
}

\begin{abstract}
Online publishing is an important factor in determining a university's ranking internationally. In formulating an effective strategy, academics need to understand the systems and criteria that are taken into account to determine the position of higher education institutions. This study was conducted to examine the understanding of PGRI University of Yogyakarta (UPY) lecturers toward the online publishing platform and the university ranking system as a measurement to identify their awareness of this field. This study used a quantitative method through a questionnaire involving 30 respondents from UPY lecturers. This study is analyzed by using descriptive analysis. The results of the study showed that the mean score of the awareness on online publishing platforms and the level of understanding of the respondents' university ranking system was at a high level. In conclusion, the findings of the study showed the knowledge and understanding of UPY lecturers on the online publishing system are good.
\end{abstract}

Keywords: Higher education, Google Scholar, Online publishing, Ranking, Scopus, Web of Science.

\section{INTRODUCTION}

In these recent years, there has been a significant improvement in the world ranking system of universities. This is due to the increment in the number of universities and the development of information technology that affects globalisation in higher education institutions as well as impacting the ranking system around the world (Sadlak, 2006). From the perspective of Hazelkorn and Gibson (2017), higher education has been partly transformed by globalisation from a community and nation-building institution to an internationalised sector fundamental to matters of competition and reputation for entities, nations, and graduates. However, the current existing university ranking system is not necessarily intended to create competition, but rather to improve the system in a university and to provide an impetus for academics to grow internationally (Rozman \& Marhl, 2008).

According to Huang (2011), the ranking system can be known as an efficient, convenient, and easily understandable evaluation method. It brings good impacts in assisting to compare and contrasting the performance of the universities that are being evaluated. Besides, the ranking system helps the university to detect their problems and identify the gap to be solved. By university ranking, also influences to get into the collaboration from a company who deciding as a partner and a funding body to invest in the research area. Therefore, the university ranking system plays an important role as to provide a quantitative and popular way to benchmark the quality and reputation of the institutions nationally and globally.

Among the main criteria in improving the reputation of the university ranking is through the publication of online journals and become a reference in the field of research. It is also supported by $\mathrm{Wu}$ (2013) that the primary outcome of educational institutions is to generate knowledge through publications and citations in high-indexed journals. Thus, there is recognition for authors through the $\mathrm{H}$-index as an evaluation of the results of referenced papers.

In addition, Rahardja et al. (2019), the H-index is an index that measures the productivity of published articles, where it is based on the number of articles published by scholars and the number of citations obtained from other articles from year to year. The higher the citation rate in other published articles, the higher the frequency of the H-Index to be able to contribute to improving the quality of the study paper (Zhang, 2013). However, if a scholar can publish many journals but has a low number of citations then it will result in a low H-index.

Corresponding Author e-mail: mnazhari@ftv.upsi.edu.my https://orcid.org/0000-0003-1756-1990

How to cite this article: Azman MNA, Permana SA, Jana $P$, Al-Muhsin MA (2022). The Online Publishing Strategies in Improving the Higher Education Institution Ranking: A Case Study of PGRI University of Yogyakarta. Pegem Journal of Education and Instruction, Vol. 12, No. 1, 2022, 193-198

Source of support: Nil

Conflict of interest: None.

DOI: $10.47750 /$ pegegog.12.01.19

Received: 19.09.2021

Accepted: 12.12.2021 Publication: 01.01.2022 
In general, there are over 20 global university ranking reports or organizations, which every have their own methodology, data resources, and indicators. However, the most prominent global ranking bodies are Google Scholar (Webometrics), Scopus (QS World University), and Web of Science (Times Higher Education \& Academic Ranking of World Universities). Through these databases, it allows scholars to have citation accounts, find out the identities of academics who refer to their research papers, and also extend the networks with other researchers (Ale Ebrahim et al., 2013). Besides, the value of the $\mathrm{H}$-index will be updated automatically from time to time for each journal, proceeding and book published in the database. Thus, Azman et al. (2014), this database evaluates the university ranking system into several criteria, which are visibility, presence, openness, and excellence of the cited papers as presented in Figure 1.

For detail of the measured criteria for the university ranking system, the visibility is based on academic materials such as journals, books, or any proceedings which easy to access and download from the online platform. Secondly, for presence, it is evaluated by the published work that can be retrieved from the various platforms which are the university repository, faculty website, Google Scholar, Scopus, and others. Meanwhile, openness is related to the website that provides files that are easy to access and download whether in PDF, Doc, Docx, or other formats. Besides, for excellence, it is for work that has been published in a high-impact journal at the international level and gives a lot of impact on the university ranking system.

Thus, the impact of online publishing plays an important role in the development of the university. However, there are a few improvements that can be made by UPY in improving its university ranking internationally such as the academician's awareness of online publishing, techniques for writing and publishing a scientific paper, strategies of the online publishing system, and others. However, by understanding on how the inner workings of rankings, and monitoring them on an ongoing basis, the university can develop its practices in ways that ultimately will influence the ranking.

The accounts' ID for the Google Scholar, Scopus Database, ResearchGate and Publons/Orcid is vital where in order to

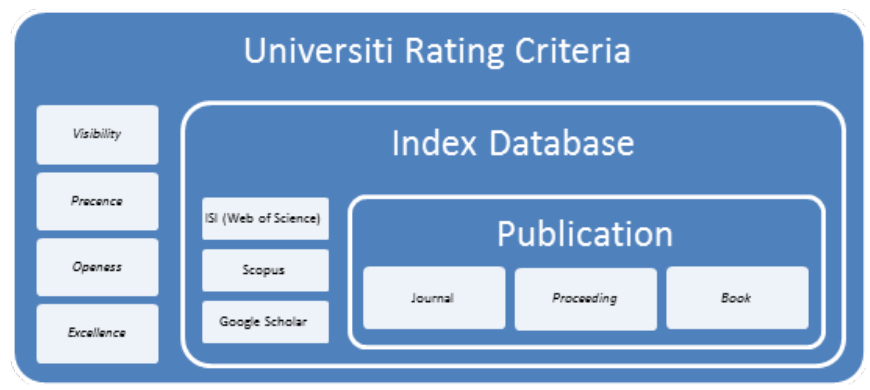

Fig. 1: Link online publications with the university rating system show their visibility works as they have a large of members and wide coverage of publications in proceedings, books and journals as presented in Table 1. The more index ID account the author has the better chances to disseminate their research works finding. The platform index ID account helps a lot the author to make sure their research works to be read and acknowledge via citation as well as have more potential to build up good networking internationally.

Hence, this study was conducted to identify the UPY academics' level of understanding in publications through online platforms such as Google Scholar, Scopus, and Web of Knowledge, and also the university ranking system to successfully achieve in becoming a world-class university. This is to ensure that they are aware and clear on the methodology of university ranking calculation. The aims of the research are to investigate the knowledge of UPY lecturers on online publishing platforms and to identify the level of understanding for the university ranking system among the UPY academicians.

\section{Methodology}

This study used is a descriptive quantitative method by surveying the knowledge and level of understanding of lecturers at UPY in online publishing strategies. Through a quantitative approach, it allows the researcher to measure the responses of the respondents involved in the study based on the questionnaires presented by analysing the problems studied concisely and accurately (Patton, 1990).

To collect the research data, the researcher used a questionnaire method in obtaining feedback from UPY lecturers. The questionnaire has three main sections which are Section A (Background), Section B (Knowledge of Online Publishing Platforms), and Section C (Knowledge of University Ranking System). Besides, the researchers used a Likert scale, with 1 for strongly disagree, 2 for disagree, 3 for unsure, 4 for agree, and 5 for strongly agree. The population of the UPY lecturer is 100. In total, there are 30 respondents were involved, that is from UPY lecturers from different faculties.

Meanwhile, the collected research data from the questionnaire were analysed using the Statistical Package

Table 1.:Accounts' ID for the Google Scholar, Scopus Database, ResearchGate and Publons in Term Number of Members and Publications

\begin{tabular}{|c|c|c|}
\hline Index ID Account & Members & Publications \\
\hline $\begin{array}{l}\text { Google Scholar } \\
\text { (Khabsa \& Giles, 2014) }\end{array}$ & 100 million & $\begin{array}{l}114 \text { million English } \\
\text { language documents }\end{array}$ \\
\hline $\begin{array}{l}\text { Scopus } \\
\text { (Elsevier, 2021) }\end{array}$ & 17 million & 81 million \\
\hline $\begin{array}{l}\text { ResearchGate } \\
\text { (ResearchGate, 2021) }\end{array}$ & 20 million & 135 million \\
\hline Publons (Publons, 2021) & 3 million & $\begin{array}{l}21,000 \text { of the world's best } \\
\text { journals }\end{array}$ \\
\hline
\end{tabular}


for Social Science (SPSS). SPSS used in this study involves data analysis using the reliability test, mean values, standard deviations and to assist in descriptive statistics. Reliability of the criteria was investigated as well. The Cronbach's alpha (a) reflects the consistency of the set of items, which theoretically a range from 0 to 1 . If a is near 0 then the quantified answers are not reliable at all, and if it is close to 1 the answers are very reliable. As a rule of thumb, if a $\geq 0.8$, then answers are reliable (Leontitsis \& Pagge 2007). The mean value for a-Cronbach in this study is 0.935 , which is higher than required. According to Sidek (2002), descriptive analysis is often conducted to provide a systematic description of the facts and characteristics of a population or field of interest factually and accurately. In addition, Goolamally and Ahmad (2002) stated that the interpretation of the mean score for the descriptive analysis was conducted based on the mean scale interval of high level (3.67 to 5.00), medium (2.34 to 3.66), and low (1.00 to 2.33).

\section{Research Findings}

\section{Respondent Background}

Respondents' background includes gender, faculty, year of service, the number of publications, and index ID account owned. In total, a total of 30 respondents out of 100 lecturers UPY were involved. Table 2 shows the data of the sample according to the background of the respondents. Through the data, male respondents are more than female respondents which are 23 lecturers (76.7\%) are male while only 7 lecturers $(23.3 \%)$ are female. This indicates that there is a significant difference in involvement between the number of male respondents which is higher than female respondents.

Based on the faculty background of the lecturers who participated in this study, the highest percentage was $80 \%$ with a total of 25 lecturers from the Faculty of Teaching and Education. Meanwhile, there are also lecturers from other faculties, with a total of 5 lecturers from the Faculty of Science and Technology (16.7\%) and only one lecturer from the Faculty of Agriculture (3.3\%).

Furthermore, the findings of the study showed the teaching experience of UPY lecturers according to their year of service. The findings indicated that 20 lecturers $(66.7 \%)$ have teaching experience between one to five years. Then, it was followed by 8 lecturers $(26.7 \%)$ who have teaching experience between 6 to 10 years. There is a lecturer (3.3\%) who has teaching experience between 11 to 15 years and also one lecturer (3.3\%) who has teaching experience for 21 years and above. This shows that the majority of UPY lecturers are still new to the field of education, which is 5 years and below.

The number of publications published by UPY lecturers was also studied. According to the data obtained, 2 lecturers (6.7\%) did not have any publication, 3 lecturers (10\%) had 1 publication and 3 lecturers (10\%) had 2 publications. Then, he was followed by 4 lecturers (13.3\%) who have 3 publications and 18 lecturers (60\%) who have publications of 4 and above. Therefore, based on the information obtained, most UPY lecturers already have online publications with several publications between 4 and above.

For the index ID account owned by lecturers at UPY, a total of 15 lecturers (50\%) only has an account at Google Scholar. While for other lecturers, at least they have more than one index ID account either Scopus Database, ResearchGate, and Publons/ Orcid. However, there are 5 lecturers (16.7\%) who have all the index IDs of Google Scholar, Scopus Database, ResearchGate, and Publons/ Orcid.

Table 2: The study sample according to the background of the respondents $(\mathrm{N}=30)$

\begin{tabular}{|c|c|c|c|}
\hline $\begin{array}{l}\text { Types of } \\
\text { Respondent }\end{array}$ & Profile & Frequency $(f)$ & $\begin{array}{l}\text { Percentage } \\
\text { (\%) }\end{array}$ \\
\hline \multirow[t]{3}{*}{ Gender } & Male & 23 & 76.7 \\
\hline & Female & 7 & 23.3 \\
\hline & Postgraduate & 0 & 0 \\
\hline \multirow[t]{9}{*}{ Faculty } & Education & 0 & 0 \\
\hline & Faculty of Business & 25 & 80.0 \\
\hline & Faculty of Teaching & 5 & 16.7 \\
\hline & and Education & 1 & 3.3 \\
\hline & Faculty of Science and & & \\
\hline & Technology & & \\
\hline & Faculty of Agriculture & & \\
\hline & 1 to 5 years & 20 & 66.7 \\
\hline & 6 to 10 years & 8 & 26.7 \\
\hline Teaching & 11 to 15 years & 1 & 3.3 \\
\hline \multirow[t]{2}{*}{ Experience } & 16 to 20 years & 0 & 0 \\
\hline & 21 years and above & 1 & 3.3 \\
\hline Number of & None & 2 & 6.7 \\
\hline \multirow[t]{4}{*}{ Publication } & 1 & 3 & 10.0 \\
\hline & 2 & 3 & 10.0 \\
\hline & 3 & 4 & 13.3 \\
\hline & 4 and above & 18 & 60.0 \\
\hline Id Index & Google Scholar & 15 & \\
\hline \multirow[t]{16}{*}{ Account } & Google Scholar, & 2 & 50.0 \\
\hline & Database Scopus & 3 & 6.7 \\
\hline & Google Scholar, & 1 & 10.0 \\
\hline & ResearchGate & 3 & 3.3 \\
\hline & Google Scholar, & 1 & 10.0 \\
\hline & Publons/ Orcid & 5 & 3.3 \\
\hline & Google Scholar, & & 16.7 \\
\hline & Database Scopus, & & \\
\hline & ResearchGate & & \\
\hline & Google Scholar, & & \\
\hline & Database Scopus, & & \\
\hline & Publons/ Orcid & & \\
\hline & Google Scholar, & & \\
\hline & Database Scopus, & & \\
\hline & ResearchGate & & \\
\hline & Publons/ Orcid & & \\
\hline
\end{tabular}




\section{The Knowledge of Online Publishing Platform Among UPY Lecturers}

Based on Table 3, the analysis of the study findings shows the level of knowledge of UPY lecturers on online publishing platforms through the medium of Google Scholar, Scopus, and ResearchGate. The overall mean of lecturers' knowledge of online platforms was at a high level, with a mean of 3.83 $(\mathrm{SD}=0.55)$. This explains that respondents are already knowledgeable about the online publishing platforms used for assessment in the university rating system internationally.

The highest mean is 4.53 which referring to two statements which are the lecturers know that Google Scholar works as an index database and lecturers also often use the Google Scholar application in their careers. For the second-highest mean, with a mean value of $4.43(\mathrm{SD}=07.3)$ with the statement that lecturers know that through Google Scholar, they can update the publication of articles either automatically and manually.

Therefore, Harzing and Van der Wal (2008) strongly encourage both individual academics and university administrators to take Google Scholar-based impact measures into account when evaluating the impact of both journals and individual academics in the areas of management and international business where they lead to a more comprehensive and possibly more accurate measure of true impact.

While based on the four (4) comparison on Google, Google Scholar (GS), Ebsco Discovery Service (EDS), and Library and Information Science Abstracts (LISA) where they were compared based on query results in terms of precision, relative recall, coverage, and full-text access. Google turned out to be the best while Google Scholar was close behind and followed by LISA and EDS (Pulikowski and Matysek, 2021).

For the lowest mean value is a mean of $2.83(\mathrm{SD}=1.21)$ which is related to the statement that the lecturers do not need the help of others while using Scopus. This means that the majority of respondents disagree with the statement. Thus, lecturers are still not fully competent to use Scopus on their own and still need the guidance of others. Figure 2 presented the 13 authors from UPY managed to publish 12 papers in 2019 but in 2021 they have improved a lot in term of number author involved and publication number increase as well.

The free access provided by the Scopus will help a lot to identify the status of the journal either valid for Scopus indexing or fall under the discontinued list. Before the author submit any paper where the publisher claim to be Scopus index, the author are required to check the status via sources (https:// www.scopus.com/sources) or Scimago website (https://www. scimagojr.com). Thus, the author able to ensure the paper have been upload to Scopus database with the correct name and right affiliation where this is important matter to give merit point to the higher education of the institution.

The mean value for the item regarding on the ResearchGate is 3.40 above shows that the lecturers of UPY are alert the benefits and being able to upload all the writing materials such as articles, proceedings, or discussion material' where able to share the research works and create the academic community to have the feedbacks and response. ResearchGate become

Table 3: Knowledge of Online Publishing Platform Among UPY Lecturers

\begin{tabular}{|c|c|c|c|}
\hline No & Statement & Mean & Standard Deviation \\
\hline 1. & I know that Google Scholar works as an index database. & 4.53 & 0.57 \\
\hline 2. & I was once exposed to the usage of Google Scholar. & 4.10 & 0.71 \\
\hline 3. & I often use Google Scholar in my career. & 4.53 & 0.63 \\
\hline 4. & I have reviewed and updated my profile on Google Scholar. & 4.37 & 0.81 \\
\hline 5. & I know that through Google Scholar I can add my article publications automatically and manually. & 4.43 & 0.73 \\
\hline 6. & The components in the Scopus Database are very easy to understand and apply. & 3.73 & 0.74 \\
\hline 7. & I know how to use the Scopus Database as a medium in finding suitable journals to publish articles. & 4.03 & 0.76 \\
\hline 8. & I do not need other's assistance when using Scopus. & 2.83 & 1.21 \\
\hline 9. & I often use Scopus Database in searching the scientific material for my research. & 3.90 & 1.12 \\
\hline 10. & I am very satisfied using the Scopus Database. & 3.80 & 1.06 \\
\hline 11. & I am adept at using ResearchGate online. & 3.40 & 0.93 \\
\hline 12. & $\begin{array}{l}\text { I know the advantage of ResearchGate is being able to upload all my writing such as articles, } \\
\text { proceedings, or discussion material. }\end{array}$ & 3.50 & 1.04 \\
\hline 13. & I always use ResearchGate to expand my network of contacts from other universities. & 3.40 & 1.00 \\
\hline 14. & If compared to other databases, I think ResearchGate is easier to use. & 3.40 & 0.97 \\
\hline 15. & I often use ResearchGate as a medium to connect and follow other academics. & 3.47 & 1.07 \\
\hline $\begin{array}{l}\text { Overall } \\
\text { Mean }\end{array}$ & & 3.83 & 0.55 \\
\hline
\end{tabular}


essential for visibility and the advantages is helps to reconnect the networking and able to communicate and leverage their recognition expertise.

\section{The Understanding of UPY Lecturers towards the University Ranking System}

Table 4 shows the knowledge of lecturers in the university ranking system through databases such as Webometrics and QS World University Rankings. The overall mean was 3.91 $(\mathrm{SD}=0.82)$. The highest mean was $4.10(\mathrm{SD}=0.84)$ which is almost all respondents agreed to the statement of the easier the publication material access and download, it increasingly affects the position of the university in Webometrics. Thus, Webometrics covering more than 31,000 Higher Education Institutions worldwide, (Webometrics, 2021). If the web performance of an institution is below the expected position according to their academic excellence, university top management should improve their visibility via website in

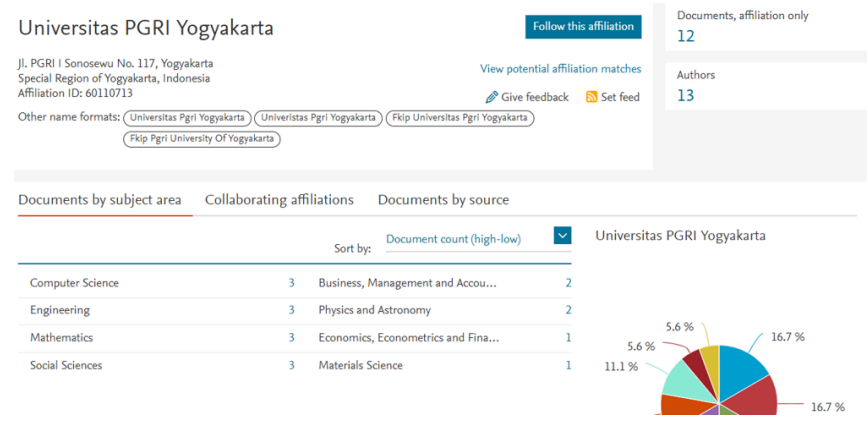

Figure 2: Scopus ID Universitas PGRI Yogyakarta in 2019 term of the open access and transparency policy, promoting substantial increases of the volume and quality of their electronic publications via repository library database. UPY rank at 134 out of 2593 Indonesia University registered under Webometrics ranking (Webometrics Indonesia, 2021).

However, there were two similar statements for the lowest mean value of $3.73(\mathrm{SD}=1.11)$ which respondents admitted that they had checked the latest university position in Webometrics. This indicates that respondents do not agree with this statement, indicating that lecturers are less concerned with checking the latest position of the university at the ranking system. Besides, the lowest mean is also 3.73 ( $\mathrm{SD}=$ 1.01) for the statement that the higher the number of citations of publications online, the higher possibility to improve the university's position in the QS World University Rankings. Thus, this proves that lecturers are not yet aware of the impact of the number of online citations on the university ranking system. UPY have not listed in the QS World Ranking and for

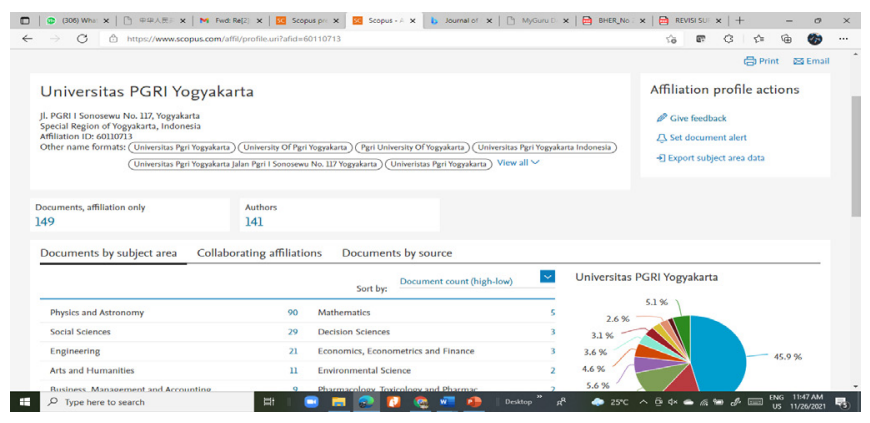

Figure 3: Scopus ID Universitas PGRI Yogyakarta in 2021

Table 4: Knowledge of University Rating System

\begin{tabular}{llll}
\hline No & Statement & Mean & Standard Deviation \\
\hline 1. & I am aware that Webometrics is a system for measuring or evaluating a university's ranking. & 4.07 & 1.08
\end{tabular}

I know that Webometrics ranks based on university websites, university repositories, Google

3. All publications that can be obtained online are very influential in the Webometrics system.

I found that the easier the publication material was to access and download, the more it influenced

6. I understand that QS World University Rankings entry data comes from the Scopus Database.

7. University rankings can be checked using the QS World University Rankings.

I know QS World University Rankings assesses the number of academic papers published in

9. international high -impact international journals

The greater the number of citations of publication materials online, the greater the university's

10. position in the QS World University Rankings. 
time being there are 16 universities out of 5190 universities in Indonesia listed in the QS World Ranking (QS, 2021; Sinta, 2021).

\section{CONCLUSION}

Through this study, it is hoped that it can help the UPY management in identifying the level of understanding of lecturers on online publications. It is important to plan further actions and strategies in raising awareness to enhance UPY's position at the university ranking system. Also, this is important as an improvement in forming an excellent education hub not only in Indonesia but also at the world level. Through the feedback, it was found that most of the respondents have a good level of knowledge and understanding of the online publishing system. As a suggestion, UPY management is encouraged to hold workshops in groups and in an organized manner to guide UPY lecturers in improving their awareness. However, this goal requires the ability and competence of university staff as it is continuous process to improve the quality of the institutions.

\section{References}

Ale Ebrahim, N., Salehi, H., Embi, M. A., Habibi, F., Gholizadeh, H., Motahar, S. M., \& Ordi, A. (2013). Effective strategies for increasing citation frequency. International Education Studies, 6(11), 93-99.

Azman, M. N. A., Majid, T. A. \& Ahamad, M. S. S. (2014). Strategi Penerbitan atas Talian dalam Meningkat Penarafan Universiti: Kes USM. Bulletin of, 15-19.

Elsevier. (2021). Content Coverage. https://www.elsevier.com/ solutions/scopus/how-scopus-works/content?dgcid=RN AGCM Sourced 300005030 (access 1 December 2021).

Goolamally, N., \& Ahmad, J. (2014). Attributes of School Leaders Towards Achieving Sustainable Leadership: A Factor Analysis. Journal of Education and Learning, 3(1), 122-133.

Hazelkorn, E., \& Gibson, A. (2017). Global science, national research, and the question of university rankings. Palgrave Communications, 3(1), 1-11.

Harzing, A. W. K., \& Van der Wal, R. (2008). Google Scholar as a new source for citation analysis. Ethics in science and environmental politics, 8(1), 61-73.
Huang, M. H. (2011). A comparison of three major academic rankings for world universities: From a research evaluation perspective. Journal of Library \& Information Studies, 9(1), $1-25$.

Khabsa, M., \& Giles, C. L. (2014) The Number of Scholarly Documents on the Public Web. PLoS ONE 9(5): e93949.

Leontitsis, A., \& Pagge, J. (2007). A simulation approach on Cron- bach's alpha statistical significance, Mathematics and Computers in Simulation 73(5): 336-340.

Patton, M. Q. (1990). Qualitative evaluation and research methods. SAGE Publications, inc.

Pulikowski, A., \& Matysek, A. (2021). Searching for LIS scholarly publications: A comparison of search results from Google, Google Scholar, EDS, and LISA. The Journal of Academic Librarianship, 47(5), 102417.

Publons. (2021). https://publons.com/about/home/ (access 1 December 2021)

QS. (2021). University Ranking Region Indonesia. https://www. topuniversities.com/university-rankings/world-universityrankings/2022 (access 1 December 2021)

Rahardja, U., Harahap, E. P., \& Dewi, S. R. (2019). The strategy of enhancing article citation and $\mathrm{H}$-index on SINTA to improve tertiary reputation. TELKOMNIKA, 17(2), 683-692.

Rozman, I., \& Marhl, M. (2008). Improving the Quality of Universities by World-University-Ranking: A Case Study of the University of Maribor. Higher education in Europe, 33(2-3), 317-329.

ResearchGate. (2021). https://www.researchgate.net/ (access 1 December 2021)

Sadlak, J. (2006). Validity of university ranking and its ascending impact on higher education in Europe. Bridges, 12(12), 13-27.

Sidek, M. N. (2002). Reka bentuk penyelidikan: Falsafah, teori dan praktis. Serdang: Penerbit Universiti Putra Malaysia.

Sinta. (2021). Affiliations. https://sinta.kemdikbud.go.id/affiliations (access 1 December 2021)

Webometrics. (2021). Second edition of 2021: Web data collected during July 2021 (the 18th year!). https://www.webometrics. info/en/current edition (access 1 December 2021)

Webometrics Indonesia. (2021). Asia Region: Indonesia. https://www. webometrics.info/en/Asia/Indonesia $\% 20$ ?page $=1$

$\mathrm{Wu}, \mathrm{J}$. (2013). Geographical knowledge diffusion and spatial diversity citation rank. Scientometrics, 94(1), 181-201. http://dx.doi. org/10.1007/s11192-012-0715-8

Zhang, C. T. (2013). The h'-index, effectively improving the h-index based on the citation distribution. PloS one, 8(4), e59912. 